\title{
The Thyristor Switched Parallel Capacitors (TSPC) converter for power factor correction in wind power systems
}

\author{
DIMITRIOS KALPAKTSOGLOU \\ Department of Electrical and Electronic Engineering \\ Metropolitan College \\ 14, El. Venizelou, 546 24, Thessaloniki \\ GREECE \\ ANASTASIOS TSIAKALOS \\ Department of Applied Informatics, \\ University of Macedonia, \\ 54006, Thessaloniki, \\ GREECE \\ MANOS ROUMELIOTIS \\ Department of Applied Informatics, \\ University of Macedonia, \\ 54006, Thessaloniki, \\ GREECE
}

\begin{abstract}
This paper presents a novel power factor correction circuit suitable for low-speed electric generators usually used in direct drive wind turbines. The Thyristor Switched Parallel Capacitors (TSPC) circuit belongs to the Controlled Series Capacitor (CSC) circuits. Those circuits have been used in power transmission lines to correct the power factor and improve the performance of the electrical system. Such a circuit can be used in wind power systems to improve and maximize the efficiency of a wind turbine. A typical direct-drive wind power system employs variable speed electric generators, but the downside is that systems like that suffer from high and variable inductive reactance. In order to correct the power factor and to improve the efficiency of the system, the inductive reactance of the generator must become equal in value to the capacitive reactance. A TSPC circuit uses a set of capacitors, connected in series with anti-parallel thyristors. In every cycle, a controller triggers the appropriate thyristors, allowing the current to pass from the capacitor which then

provides the system with the capacitive reactance that matches the generator's inductor reactance. Therefore, the TSPC circuit is able to counteract for any reactive losses and improve the power factor, as well as, the efficiency. This paper introduces this novel power factor correction circuit that employs capacitors in parallel configuration. This circuit was simulated in PSPICE and was implemented and tested in the lab. Based on the simulation and implementation results, we discuss the benefits as well as the drawbacks of the proposed circuit.

Key-Words: - reactive power control, phase control, thyristor circuits, switching converters.
\end{abstract}

Received: December 12, 2020. Revised: July 25, 2021. Accepted: July 30, 2021. Published: August 4,

2021.

\section{Introduction}

CURRENTLY, our civilisation's economy is based upon petroleum substances, which have been proven to be extremely destructive and very harmful to the environment and to human health.

In order to reduce greenhouse gases, conventional fuels should be replaced by Renewable Energy Sources and therefore Wind Turbines have been developed to convert the wind energy into electricity. A typical wind turbine, as shown in Figure 1, consists of a tower, a hub, the blades and the nacelle which houses a speed-up gearbox as it is essential to increase the slow rotation of the shaft to high speed suitable for the electric generator.

To reduce the maintenance cost of a gearbox and to make the wind turbine more fault-tolerant, 
gearless or direct-drive wind turbines have been used which are more efficient as the rotor is the only moving part that transfers the energy from the blades to the electric generator via a low-speed shaft. Those wind turbines eliminate gearboxes by replacing them with variable speed electric generators and solid-state electronic converters.

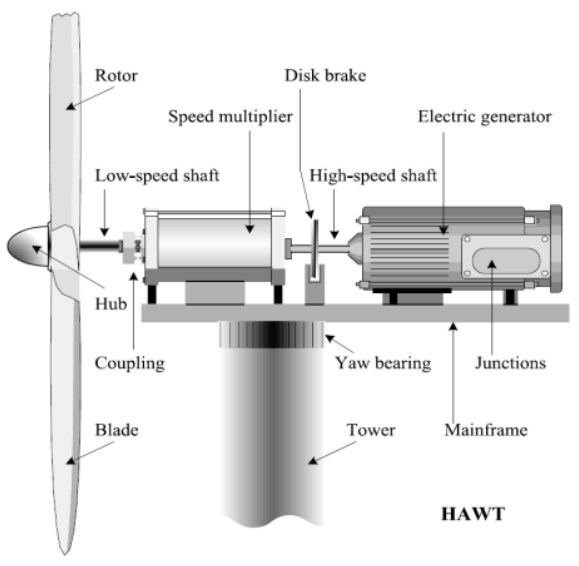

Fig.1: Schematic diagram of equipment contained in a nacelle of a HAWT [4]

Direct-drive wind turbines operate within a certain rpm range, and the output voltage and frequency from the direct-coupled generator vary over time. Therefore, these systems rectify the output three-phase voltage from the generator to DC. A DC link and inverter convert the DC voltage to become suitable for transmitting it to the electrical grid. The rectification process could be done using a simple Uncontrolled Diode Bridge rectifier but in this case the system's efficiency is low as there is no any power factor correction technique.

\section{Operation with an Uncontrolled Single-Phase Diode Bridge Rectifier}

The distribution system operator would expect the control of renewable energy sources, so that they contribute to the network with constant voltage and frequency, in accordance with national standards. However, in wind turbines the output voltage and frequency change depending on the abrupt changes in wind speed. Therefore, the solution to this problem of constantly changing output is to convert it to DC voltage using a rectifier and then to AC signal, in the same voltage and frequency as those of the distribution network. An arrangement that would make this feasible is shown in Figure 2

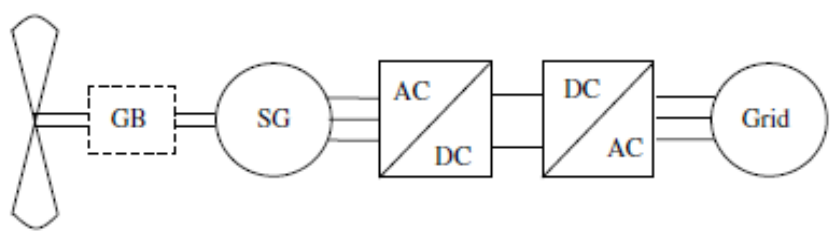

Fig.2: Wind turbine with synchronous generator [5].

Figure 2 shows the structure of the wind turbine. We can see on the left side the rotor of the wind turbine and its connection to an electric generator (SG) through a gearbox (GB). What follows is a rectifier (AC / DC) to convert $\mathrm{AC}$ to DC. A DC filter that was placed at the output of the rectifier to normalize the DC voltage generated, followed by a converter (DC / AC). A transformer is connected to the output of the inverter to increase the AC voltage of the inverter creating the necessary conditions for the wind turbine to be connected to the power grid [6-9]. The converter can be either a SCR controller or a PWM converter, depending on the situation [5].

Due to lower cost, all modern wind turbine systems use a two-phase bridge rectifier to rectify the energy generated, from AC to DC. AC / DC conversion typically uses a voltage feedback test. However, there is no feedback loop in the uncontrolled diode bridge rectifier. As a result, the output voltage is completely dependent on the amplitude of the input voltage. For simplicity Figure 3 shows a schematic diagram of the single-phase rectifier used in wind turbines.

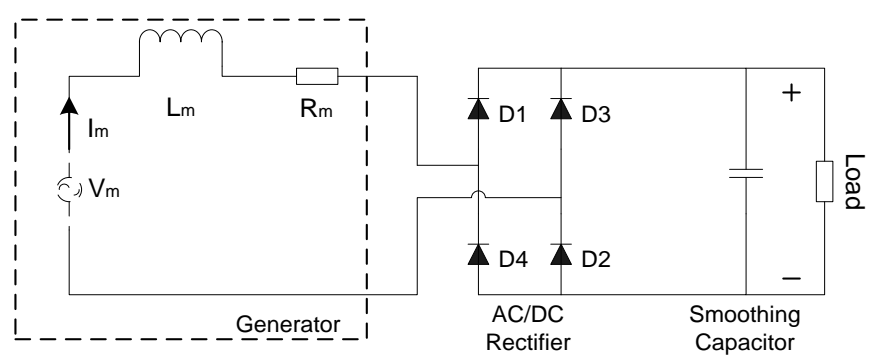

Fig.3: Standard single-phase rectifier circuit

The rectifier we describe essentially converts any AC input to DC. Depending on the half-life of the alternating current, we also have the corresponding treatment of the diodes. The result is the creation of a constant voltage at the output of the rectifier. Figure 4 below shows the simulation results for the typical single-phase rectifier circuit. 




Fig.4: Generator back EMF and the fundamental current waveform showing the effects of generator inductance [10].

The inductive generator results in the voltage not being tangential to the current in the circuit. This phase shift results in losses of available power that could be transferred from the generator to the grid. Hence, a way is needed to counteract the inductive loads and achieve maximum power transfer.

Assuming a purely sinusoidal back emf voltage, the generator power output $\mathrm{P}$ is given by the following Equation:

$$
P=V_{m} I_{m 1} \cos \alpha
$$

where $\alpha$ is the phase angle between $\mathrm{V}_{\mathrm{m}}$ and $\mathrm{I}_{\mathrm{m} 1} \cdot \cos \alpha$ can take values between 0 and 1 . When $\cos \alpha$ is 0 then all the available power $\mathrm{P}$ becomes reactive and the real power is equal to 0 . Minimising the angle $\alpha$, $\cos \alpha$ will increase and thus the real power delivered to the load will clearly increase. This can be achieved if a Series Resonant Circuit (series RLC) is used.

In a series-resonant RLC circuit the inductive reactance of the inductor becomes equal in value to the capacitive reactance of the capacitor. In other words, $\mathrm{X}_{\mathrm{L}}=\mathrm{X}_{\mathrm{C}}$. The point at which this occurs is called the Resonant Frequency point, $(f r)$ of the circuit, and the maximum power is delivered when the system works at this resonant frequency point [10].

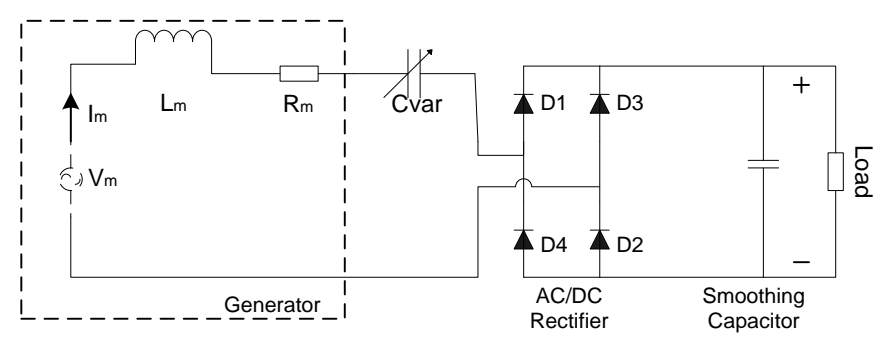

Fig.5: Generator with variable capacitor [10]

To achieve the desired result, it is necessary to use a variable capacitor as shown in Figure 5, designed to operate at high voltage and high current. However, it is not commercially available.
Controlled series rectifiers (CSCs) could be used as a solution.

\section{Thyristor Switched Parallel Capacitor Rectifier (TSPC)}

One way to overcome the lack of a variable capacitor is the use of the Thyristor Switched Series Capacitor (TSSC) rectifier but it uses a large amount of capacitor blocks connected all in series. Therefore, this paper proposes to stack fixed value capacitors in a parallel connection configuration. In this configuration, the block consists of 2 antiparallel thyristors connected in series to a capacitor, where each capacitor has a different value, and the total capacitance is $\mathrm{C}_{\mathrm{T}}$.

Figure 6 shows the PSpice model for the TSPC circuit. In order to correct the power factor and to improve the efficiency, the generator's inductive reactance must have the same value as the system's capacitive reactance. Therefore, in every cycle, the controller triggers the appropriate thyristors, allowing the current to pass from the capacitor, which will then provide the system with the capacitive reactance that matches the generator's inductor reactance. It must be added that the switching devices can be controlled using an FPGA or a microcontroller. The use of a computational system to control the switching devices is inevitable and the simplicity of the algorithm does not degrade the system's reliability.



Fig.6: The PSpice model for the TSPC circuit

As it was mentioned before, each block uses different values of capacitors. These values are shown in the Table I below. 
Table 1. Capacitor Values

\begin{tabular}{|c|c|c|}
\hline $\begin{array}{c}\mathbf{\omega} \\
(\mathbf{r p m})\end{array}$ & $\begin{array}{c}\text { Single Capacitor } \\
\text { value (mF) }\end{array}$ & $\mathbf{m}$ \\
\hline 6 & 358 & 1 \\
\hline 8 & 17,1 & 1 \\
\hline 10 & 10,2 & 1 \\
\hline 12 & 1,9 & 1 \\
\hline 14 & 0,97 & 1 \\
\hline 16 & 0,55 & 1 \\
\hline 18 & 0,34 & 1 \\
\hline 20 & 0,22 & 1 \\
\hline
\end{tabular}

This configuration requires only 1 active block, and therefore, the $\mathrm{m}$ value for all the frequencies is equal to 1 . It is clearly shown that it is feasible to drastically reduce the number of blocks used in TSSC. In addition, the resistive losses of the thyristors will be reduced. The simulation results using the TSPC circuit are shown in Fig 7 and 8.

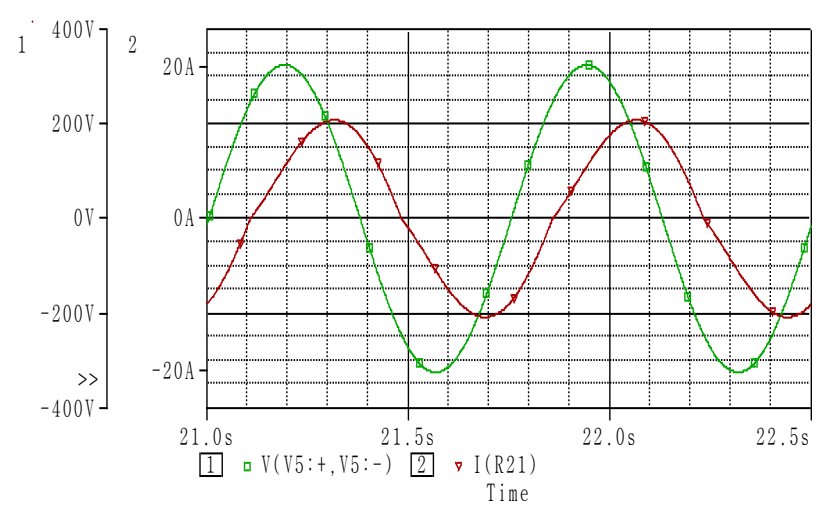

Fig.7: The voltage and current waveforms before the insertion of the TSPC circuit.

Figure 7 shows the phase delay between the current and the voltage. This system has low power factor and it suffers from reactive losses.

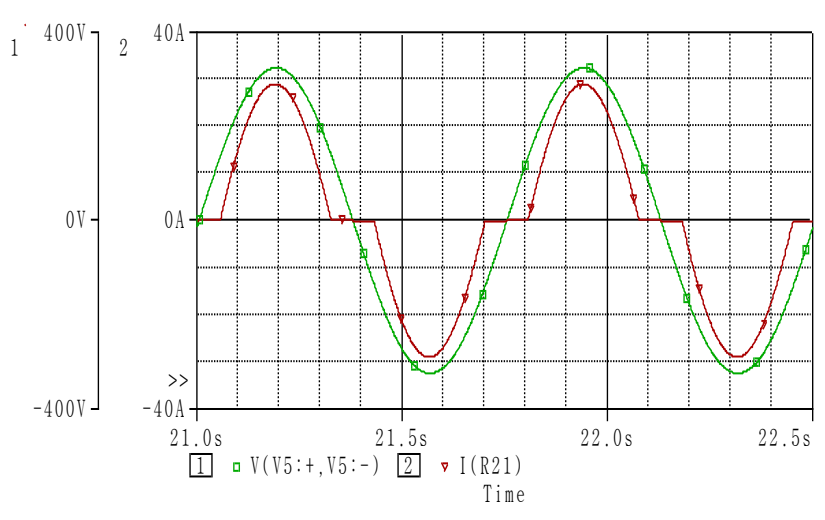

Fig.8: The voltage and current waveforms after the insertion of the TSPC circuit.

Figure 8 shows the voltage and the current lines after the insertion of the proposed TSPC circuit. The power factor is nearly 1 and the efficiency is greatly improved. The simulation results for the phase current, output voltage and the output power of the TSPC circuit are presented in Figures 9, 10 and 11.

All the simulation results regarding the phase current, the output voltage, and the output power using a $1.5 \mathrm{kVA}$ PMSG model in PSpice are shown in Figure 9 and Figure 10 below.



Fig.9: Phase current vs PMSG speed

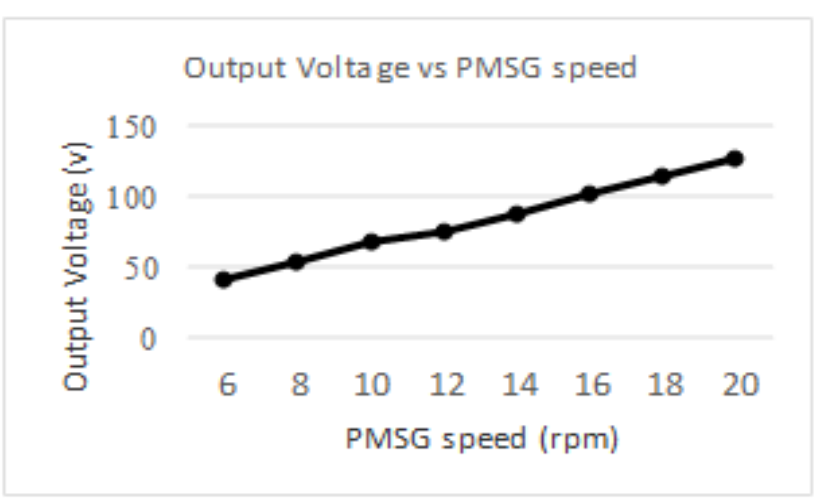

Fig.10: Output Voltage vs PMSG speed 
Figure 9 and Figure 10 show the phase current and the output voltage in relation to the generator's speed respectively. Figure 11 shows the output power in relation to the generator's speed.

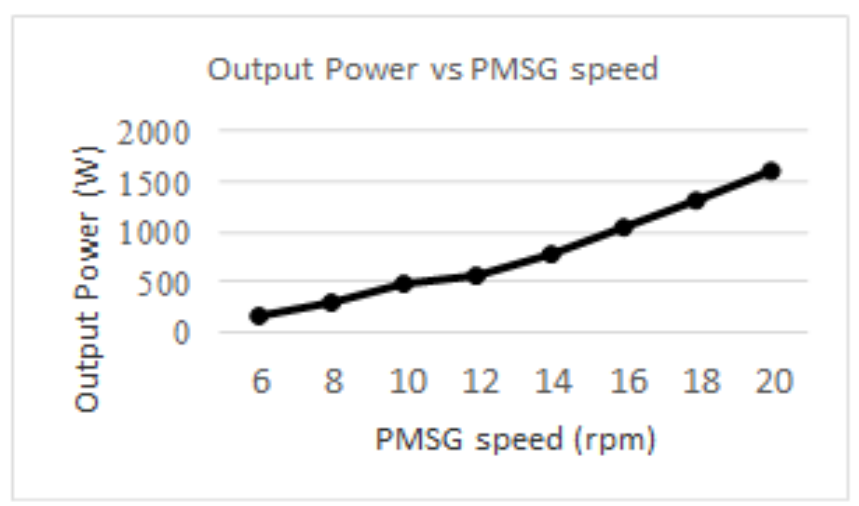

Fig.11: Output Power vs PMSG speed

It can be clearly seen that the output power is very close to the ideal case, and similar to the TSSC circuit results. The only difference is that lower values of capacitors have been used. In addition, the resistive load is much lower, due to fact that only 1 block, meaning only 1 pair of anti-parallel thyristors are active.

\section{Laboratory experiment}

The frequency of the wind turbine must first be measured by using a zero frequency detection circuit. That is, we reduce the operating voltage with a transformer and measure the operating frequency. Basically, it counts for the half-period of the signal. Therefore, we know the time of the half period.

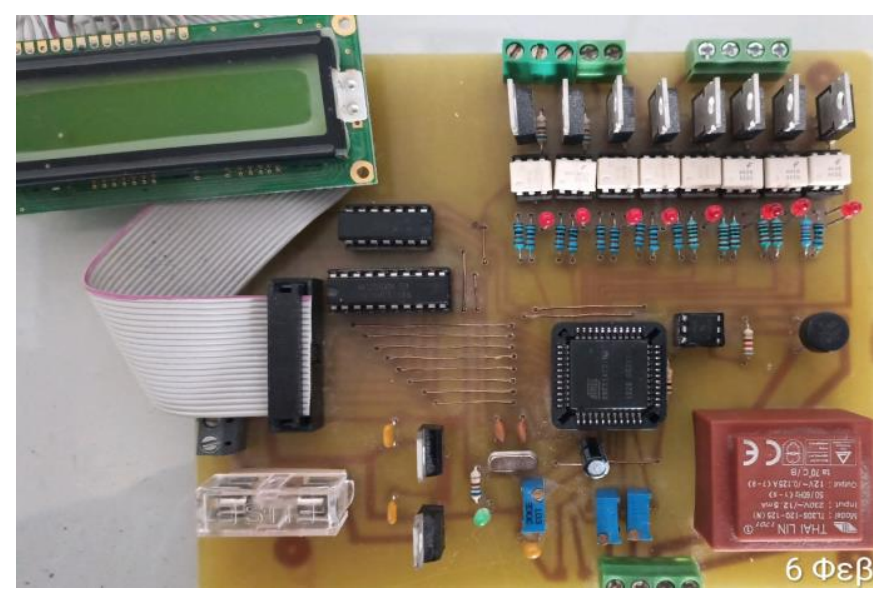

Fig.12: Application development board
Figure 12 shows the control board of the system which essentially reads the frequency of the generator and connects the capacitors in the system.

Follows figure 13 that presents arrays of capacitors which are used sequentially in the circuit to achieve the desired result.

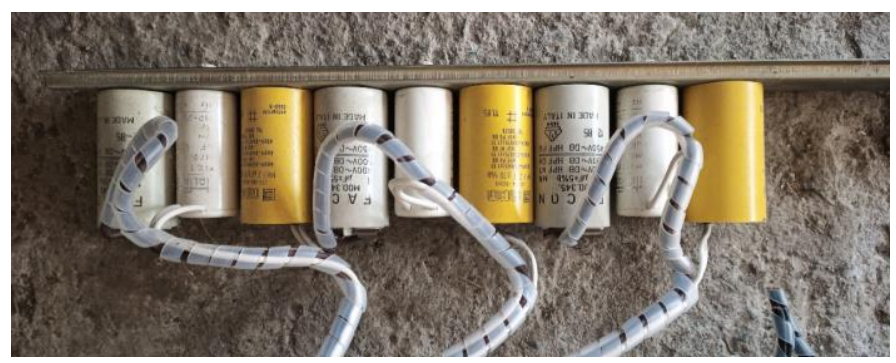

Fig.13: The array of capacitors

The measurement is done in one phase of the system which is representative for the whole system. The microcontroller counts the frequency of the network signal and reads from an internal table the output it should activate. Of course, time is essentially a period of time within which this output is activated. The microcontroller essentially changes the output so it changes the values of the capacitors to which they are connected in the circuit. In case of a capacitor failure, the controller calculates the capacitance that is needed, at that point. By combining two or more capacitors, the capacitive reactance matches the inductive reactance resulting in power factor correction.

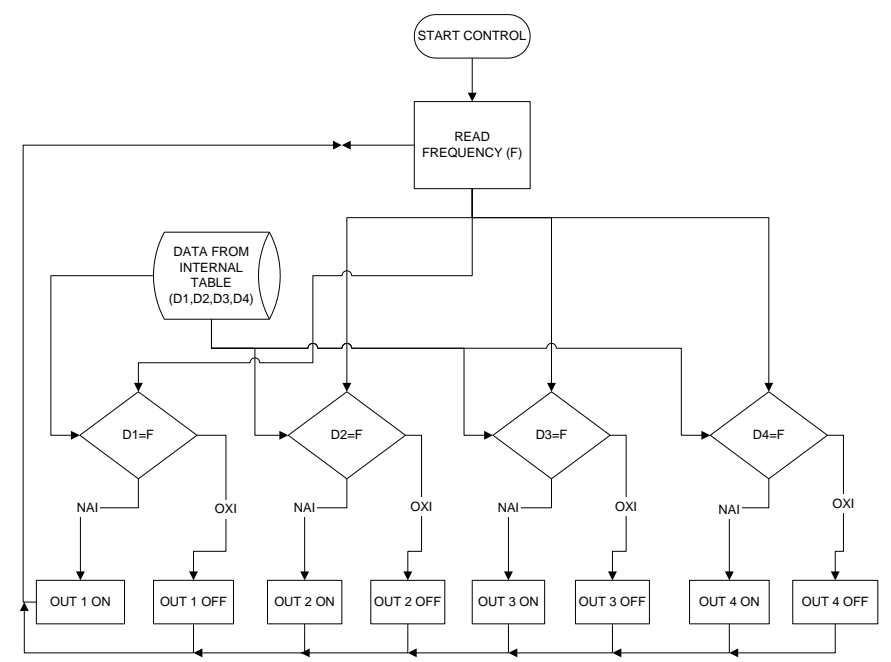

Fig.14: The array of capacitors

The flow diagram of the circuit operation shows the operation of the application. Depending on the 
half-life of the AC input signal frequency, the corresponding output is activated which places the capacitor inside the circuit. Here is an alternative application that essentially replaces the variable capacitor.

The following diagrams showing the change in wind turbine output using the correct capacitor capacitance. The wind turbine output signal is presented before and after the improvement with the use of a capacitor. Figure 15 and figure 16 shows the results before and after the insertion of the TCSP circuit into the system. Figure 15 shows the phase delay between the back emf voltage and phase current.

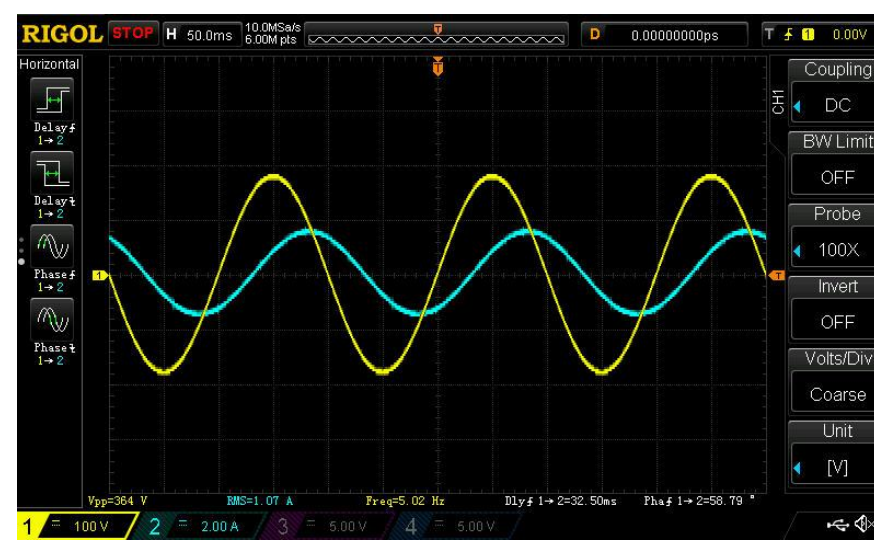

Fig.15: The array of capacitors

Figure 16 shows that with the insertion of the TCSP into the system the phase between the back emf and the phase current is almost zero, which has as a result almost unity power factor. Power factor correction enables maximum power transfer of the generated power, which improves generator's efficiency. The proposed circuit model can be easily applied to any generator by simply changing capacitors' values.



Fig.16: The array of capacitors

\section{Conclusion}

In this paper, the operation of a wind turbine was studied and, in particular, the operation without the use of a gearbox but with the use of direct drive system. For the correct operation of the generator while connected to the grid, it is imperative to increase the voltage of the generator as well as its frequency in the frequency of the grid. The solution to this problem is to convert the current, through a rectifier bridge, to DC and then with an inverter to $\mathrm{AC}$, for subsequent connection to the grid. However, this topology has a low power factor due to the high inductive response of the generator. Modern rectifiers use PWM to convert alternating current AC signal to DC but such rectifiers have very high switching losses due to the high switching frequency [20].

The solution proposed is a controlled series of capacitors to compensate for the inductive reaction of the generator. This methodology can be applied to variable frequency, variable voltage systems such as wind turbines. The requirement is to correct the operating power factor of the inverter, in the whole operating frequency range and thus to maximize the energy conversion of the wind turbine.

The PWM rectifier uses high switching frequency, to achieve power factor correction, which results in high switching losses. However, the TCSP uses low switching frequency, which is the frequency of the direct-drive wind turbines' generator. This new circuit uses only one capacitor, for each change in system's frequency. A standard diode bridge rectifier circuit, an 1.5KVA PMSG, and a suitable control board for TSPC circuit were tested in the lab. It was proved that by using a 
suitable capacitor array, a maximum transfer of the generated power to the load was achieved.

\section{Appendix:}

PMSG parameters:

Maximum output volt-amperes: $1.5 \mathrm{kVA}$

Maximum back EMF \& Current: 230V

Maximum Current: 16A

Winding resistance: $6.4 \Omega$

Winding inductance: $384 \mathrm{mH}$

References:

[1] M. P. Dave and N. Kumar, "Auxiliary controlled SVS and controlled series compensation for flexible AC transmission systems," Proceedings of International Conference on Power Electronics, Drives and Energy Systems for Industrial Growth, vol.1. pp. 121-127, 1996.

[2] Marcelo De Lellis Costa de Oliveira, Airborne Wind Energy with Tethered Wings: Modeling, Analysis And Control, Ph.D. dissertation, Federal University of Santa Catarina, Florianopolis, 2016.

[3] S. Kalogirou, Solar energy engineering: processes and systems. Amsterdam; London: Elsevier/Academic Press, 2009.

[4] R. Carriveau and InTech Open Access Books. Fundamental and Advanced Topics in Wind Power. Available: http://www.intechopen.com/books/fundamentaland-advanced-topics-in-wind-power, 2011.

[5] T. Wildi, Electrical machines, drives, and power systems, 6th ed., International ed. ed. Upper Saddle River, N.J.: Pearson Education International, 2006.

[6] M. Hannachi and M. Benhamed, "Modeling and control of a variable speed wind turbine with a permanent magnet synchronous generator,"2017 International Conference on Green Energy Conversion Systems (GECS), Hammamet, pp. 16, 2017.

[7] M. Mirzaei and S. M. R. Mirjalili, "Direct drive field winding synchronous generators for medium power wind turbines,"6th IET International Conference on Power Electronics, Machines and Drives (PEMD 2012), Bristol, pp. 1-4, 2012.
[8] K. Patil and B. Mehta, "Modeling and simulation of variable speed wind turbine with direct drive permanent magnet synchronous generator,"2014 International Conference on Green Computing Communication and Electrical Engineering (ICGCCEE), Coimbatore, pp. 1-6, 2014.

[9] E. N. López-Ortiz, D. Campos-Gaona and E. L. Moreno-Goytia, "Modelling of a wind turbine with permanent magnet synchronous generator,"2012 North American Power Symposium (NAPS), Champaign, IL, pp. 1-6, 2012.

[10] V. Pickert, B. Zahawi, and D. Kalpaktsoglou, "Forced commutation controlled series capacitor (FCSC) circuit applied to stand-alone wave energy conversion buoys," Journal of Marine Engineering and Technology, vol. 10, pp. 1523,2011.

[11] B. D. Deotaleand S. R. Paraskar, "Transient stability improvement using Thyristor Switched Series Capacitor (TSSC) FACTS device," in 2016 IEEE Students' Conference on Electrical, Electronics and Computer Science (SCEECS), Bhopal, India, pp. 1-6., 2016.

[12] V. Pickert, D. Kalpaktsoglou, and A. AlBusaidi, "Controlled series capacitor converters applied in generator-sets for SHEV's," in 24th International Battery, Hybrid and Fuel Cell Electric Vehicle Symposium and Exhibition 2009, EVS 24, Stavanger, pp. 1599-1603, 2009.

[13] B. S. Joshi, O. P. Mahela and S. R. Ola, "Implementation of Thyristor controlled series capacitor in transmission system to improve the performance of power system network,"2017 4th International Conference on Power, Control \& Embedded Systems (ICPCES), Allahabad, pp. 1-6, 2017.

[14] N. Johansson, L. Angquist and H. Nee, "An Adaptive Controller for Power System Stability Improvement and Power Flow Control by Means of a Thyristor Switched Series Capacitor (TSSC)," in IEEE Transactions on Power Systems, vol. 25, no. 1, pp. 381-391, Feb. 2010.

[15] B. S. Rigby, C. K. Ndlovu and R. G. Harley, "A thyristor-controlled series capacitor design for research laboratory application,"1999 IEEE Africon. 5th Africon Conference in Africa (Cat. No.99CH36342), Cape Town, South Africa,vol.2, pp. 903-908, 1999.

[16] M. Gheydi, P. Farhadi, S. Bagheri and A. Hematizadeh, "Impact of wind farm and thyristor-switched series capacitors in voltage, active and reactive power in normal condition of network," 10th International Symposium on 
Advanced Topics in Electrical Engineering (ATEE), pp. 693-698, 2017.

[17] W. Aslam, Y. Xu, A. Siddique and F. M. Albatsh, "Implementation of series facts devices SSSC and TCSC to improve power system stability," 13th IEEE Conference on Industrial Electronics and Applications (ICIEA), pp. 22912297, 2018.

[18] T. F. Chan and L. L. Lai, "Permanent-Magnet Machines for Distributed Power Generation: A Review," in 2007 IEEE Power Engineering Society General Meeting, pp. 1-6, 2007.

[19] P. J. Pyrhonen, and P. Kontkanen, "Axial Flux Permanent Magnet Generator with Concentrated Winding for Small Wind Power Applications," in IEEE International Conference on Electric Machines and Drives, pp. 1187-1191, 2005.

[20] D. A. F. Collier and M. L. Heldwein, "Modeling and design of a micro wind energy system with a variable speed wind turbine connected to a permanent magnet synchronous generator and a PWM rectifier, "in Power Electronics Conference (COBEP), Praiamar, Brazil, pp 292-299, 2011.

[21] K. Subramanian, K. K. Ray, Synchronised Linear Ramp-Pulse Based Triggering Pulse Generation ON/OFF Control for Solid-State Switches: Capacitor Switching Applications, WSEAS Transactions on Power Systems, pp. 45-49, Issue 2, Volume 7, April 2012.

[22] R. Carbone, A passive power factor correction technique for single-phase thyristor-based controlled rectifiers, International Journal of Circuits, Systems and Signal Processing, pp.169-179, Issue 3, Volume 2, 2008.

[23] M. Nayeripour, M. M. Mansouri, Coordination of Overcurrent Protection and Fault Ride through Requirements of Doubly Fed Induction Generator in a Wind Turbine, International Journal of Mathematics and Computers in Simulation, pp.107-112, Volume 13, 2019.

\section{Contribution of individual authors to the creation of a scientific article (ghostwriting policy)}

Dimitrios Kalpaktsoglou carried out the simulation and the optimization.

Anastasios Tsiakalos carried out laboratory experiments.

Manos Roumeliotis was responsible for the editing of the paper.
Creative Commons Attribution License 4.0 (Attribution 4.0 International, CC BY 4.0)

This article is published under the terms of the Creative Commons Attribution License 4.0 https://creativecommons.org/licenses/by/4.0/deed.en US 